\title{
Intrauterine Exposure to Alcohol and Tobacco Use and Childhood IQ: Findings from a Parental-Offspring Comparison within the Avon Longitudinal Study of Parents and Children
}

\author{
ROSA ALATI, JOHN MACLEOD, MATTHEW HICKMAN, KAPIL SAYAL, MARGARET MAY, GEORGE DAVEY SMITH, AND
} DEBBIE A. LAWLOR

\begin{abstract}
School of Population Health [R.A.], University of Queensland, Herston, Queensland, 4006 Australia; Department of Social Medicine [J.M., M.H., M.M., G.D.S., D.A.L.], University of Bristol, Bristol, BS8 2PR United Kingdom; School of Community Health Sciences [K.S.], University of Nottingham, Nottingham, NG7 2UH United Kingdom
\end{abstract}

\begin{abstract}
This study aims to test the hypothesis that moderate maternal alcohol and tobacco use in pregnancy is associated with intelligent quotient (IQ) scores in childhood through intrauterine mechanisms. We conducted parental-offspring comparisons between the associations of tobacco and alcohol consumption with child's IQ in the Avon Longitudinal Study of Parents and Children. Analyses were conducted on 4332 participants with complete data on maternal and paternal use of alcohol and tobacco at 18 wk gestation, child's IQ and a range of confounders. IQ was measured at child age 8 with the Weschler Intelligence Scale for Children (WISC-III). We used multivariable linear and logistic regression to estimate mean differences and $95 \%$ confidence intervals in IQ scores across the exposure categories and computed $\mathrm{f}$ statistics to compare maternal and paternal associations. In fully adjusted models, there was no strong statistical evidence that maternal alcohol and tobacco consumption during pregnancy were associated with childhood IQ with any greater magnitude than paternal alcohol and tobacco consumption (also assessed during their partners' pregnancy). Our findings suggest that the relationship between maternal moderate alcohol and tobacco use in early pregnancy and childhood IQ may not be explained by intrauterine mechanisms. (Pediatr Res 64: 659-666, 2008)
\end{abstract}

$\mathrm{E}$ xisting evidence suggests that the development of intelligent quotient (IQ) is associated with exposures affecting brain growth during the fetal period, but also factors operating during an individual's life course (1-4). It is well established, for example, that excessive alcohol use in pregnancy can cause a variety of poor developmental outcomes, better known as the Fetal Alcohol Syndrome (5). Whether exposure to lower levels of alcohol consumption in pregnancy affects the development of more subtle cognitive difficulties is less well established. It is also unclear whether intrauterine exposure to tobacco affects later cognitive development.

The evidence of a negative association between moderate fetal exposure to alcohol and later IQ is not conclusive. A metaanalysis based on nine studies with a total of 3585 infants

Received April 29, 2008; accepted July 18, 2008

Correspondence: Rosa Alati, Ph.D., School of Population Health, The University of Queensland, 1st Floor, Public Health Building, Herston Rd, Herston Queensland 4006 Australia; e-mail: r.alati@sph.uq.edu.au

Supported bythe UK Medical Research Council, the Wellcome Trust, and the University of Bristol provide core support for ALSPAC.

This article contains supplementary materials, which can be found online at www. pedresearch.org examined the effect of alcohol exposure in pregnancy on infant mental development using the Mental Developmental Index scores (6). Analyses were conducted separately for infants who were $6-8,12-13$, and 18-26 mo-old. In models that adjusted for parity, birth weight, gestational age, maternal intelligence quotient (IQ), education, tobacco, and drug use during pregnancy, there was an association between maternal reports of drinking $2+$ drinks per day compared with no alcohol for infants aged 12-13 mo [mean difference in Mental Developmental Index score -0.53 (95\% CI: $-1.02,-0.04)$ ], but not for younger infants, aged $6-8$ mo $[-0.07(-0.16,+0.02)]$, or older infants, aged $18-26$ mo $[+0.07(0.00,+0.13)]$. However, there was no strong statistical evidence of heterogeneity by age in these adjusted analyses.

Results from studies of older children are also mixed. In the Seattle Prospective Longitudinal Study on Alcohol and Pregnancy, inverse associations between moderate maternal alcohol consumption and binge patterns of drinking during pregnancy and offspring IQ have been consistently found at all offspring ages from 7 to 14 y (7-9). In a large Australian prospective study, only "binge" drinking was found to be inversely associated with Raven's score at age 14 (10). In other studies moderate maternal alcohol consumption during pregnancy was not associated with offspring IQ (11), but was associated with deficits in learning and short-term memory $(12,13)$, after adjustment for maternal socio-economic position, IQ, mental health and substance use. Only the Seattle cohort included adjustment for paternal alcohol consumption.

Inferences of an intrauterine effect of tobacco use on the development of IQ in childhood have also been made. Several studies $(1,14-20)$ have found decreases in IQ scores ranging from 2.9 to 6.0 points in children of mothers who smoked during pregnancy compared with children of mothers who did not, although in two analyses the strength of the association was considerably reduced after adjustment for confounders $(16,20)$. Most studies have not been able to adequately separate in utero exposure with environmental smoking exposure during the postnatal years $(15,16,21,22)$, and paternal tobacco

Abbreviations: ALSPAC, avon longitudinal study of parents and children; IQ, intelligent quotient; WISC-III, weschler intelligence scale for children 
use during pregnancy was adjusted for in only one study (16). Finally, two recent reports $(1,18)$ found that parental education and their intelligence (assessed by IQ tests) confounded the relationship between maternal smoking in pregnancy and child's IQ.

Some propose that the toxic effects of metabolic products of alcohol and tobacco may affect the developing brain after crossing the placenta whereas others have suggested that shared familial factors, rather than a specific intrauterine toxic effect, may confound any link between maternal smoking during pregnancy and later offspring IQ $(1,18)$. Parental use of alcohol and tobacco has been found to vary according to parental social position-so apparent effects of these exposures could be due to confounding by other socially patterned exposures.

A common method of addressing this issue is to adjust for family socioeconomic background and other potential confounding factors (18). However, this may be inadequate given the very strong association of socioeconomic position with both exposures (smoking and alcohol) and outcome (childhood IQ) and the difficulty of fully measuring socioeconomic position with just one or two indicators.

One method of further exploring the extent to which any association is explained by shared familial and environmental factors, as opposed to intrauterine mechanisms, is to compare the magnitude of associations of maternal alcohol and tobacco consumption during pregnancy with offspring IQ to that of the equivalent paternal associations (23). If the association of paternal alcohol or tobacco use with offspring IQ is the same as that of the equivalent maternal association, this would provide evidence against a specific intrauterine effect of these exposures and, suggest that any apparent relationship between maternal alcohol/tobacco use in pregnancy and child's IQ is more likely to reflect confounding by shared socioenvironmental or other familiar factors. If, on the other hand, associations of maternal alcohol or tobacco consumption during pregnancy with offspring IQ are stronger than those of the equivalent paternal associations, this would support an intrauterine effect of these exposures. The use of maternal-paternal comparisons with offspring outcomes has face validity as a method to distinguish intrauterine from other mechanisms. The strong association between maternal smoking during pregnancy and lower birth weight [mean difference between those who were smoking during pregnancy and those who were not adjusted for potential confounding factors and paternal smoking: $-158.6 \mathrm{~g}$ [95\% CI: $-178.2,-138.9$ )], was not seen in the paternal associations of smoking with birth weight [mean difference: $-8.4 \mathrm{~g}$ [95\% CI: $-26.6,+9.8)$ ], with strong evidence of a statistically robust difference $(p<$ 0.001) (23).

The aim of this study is to investigate whether intrauterine exposure to moderate levels of alcohol consumption and to tobacco consumption exerts a causal influence on offspring IQ at age $8 \mathrm{y}$. We aim to test this hypothesis by comparing the magnitudes of the associations of maternal consumption of alcohol and tobacco with offspring IQ with the corresponding associations with paternal consumption of alcohol and tobacco.

\section{METHODS}

Data from the Avon Longitudinal Study of Parents and Children (ALSPAC) were used. ALSPAC is a prebirth cohort study of children born to mothers resident in the former Avon region in the South West of England while pregnant (http://www.alspac.bris.ac.uk/welcome/ index.shtml). Participants enrolled in the study included all pregnant women residing in the area, who were due to give birth between April 1991 and December $1992(n=14,541)$. The characteristics of the sample, its representativeness and details of the phases of the study are provided elsewhere (24) and on the study website (http://www.alspac.bris.ac.uk/ welcome/index.shtml). Informed consent has been obtained from participants, and ethical approval for the study was obtained from the ALSPAC Law and Ethics Committee and the Local Research Ethics Committees.

The sample for the present study includes all singleton babies still alive at $1 \mathrm{y}$, for whom data were collected from mothers and partners at approximately 8 and $18 \mathrm{wk}$ gestation (for the assessment of maternal and paternal alcohol and smoking) and from the assessment conducted as part of the Focus visit (clinic assessments) of the children at age 8 .

Outcome: The Weschler Intelligence Scale for Children (WISC-III ${ }^{U K}$ ). The WISC-III ${ }^{\mathrm{UK}}$ was used to assess cognitive function when children were $8 \mathrm{y}$ of age. The WISC-III ${ }^{\mathrm{UK}}$ is a widely used individual ability test to assess cognitive function in children (25). The WISC comprises 10 subtests: five verbal and five performance. To reduce the length of the session, a short form of the measure with alternate items was used for all subtests. Raw scores were calculated according to the items used in the alternate item form of the WISC (26). This was achieved by summing the individual items within each subtest and multiplying by two for six of the subtests, multiplying by $5 / 3$ for the similarities subtest, and multiplying by $3 / 2$ for the object assembly and block design subtests. This made the raw scores comparable to those that would have been achieved had the full test been administered.

Then, age-scaled scores were obtained according to the WISC developer's instructions, and total scores were calculated for the Performance, Verbal scales, and total IQ. The final WISC IQ scores, (verbal, performance, and total IQ measures) were calculated from the total scaled scores and standardized by ALSPAC researchers on a normal British population (taking account of age and gender) to have a mean of 100 and SD of 15 . These scores were used as the outcome measures in this study. We also analyzed associations with low IQ, defined as a score of 79 or below (based on official qualitative descriptions of WISC-III ${ }^{\mathrm{UK}}$ IQ scores) (25), to determine whether associations with IQ as a continuous variable masked important associations with low intelligence (an important developmental and clinical outcome). About $421(6.5 \%)$ of the participants for whom WISC-III scores were available were classified as having low IQ scores.

Main exposures: Maternal and paternal alcohol and tobacco use. Main exposures included maternal and paternal use of alcohol and tobacco. Two measures of alcohol use were available at $18 \mathrm{wk}$ gestation. First, women were asked how often they had drunk alcoholic drinks during the first 3 mo of pregnancy (Never, Less than one glass a week, at least one glass a week, at least 1 or two glasses every day, at least 3-9 glasses every day, and at least 10 glasses every day). The following footnote was included "by glass we mean a pub measure of spirits, half a pint of lager or cider, a wine glass of wine." The variable was recoded into Never, $<1,1+\mathrm{wk}, 1+/ \mathrm{d}$. More severe patterns of daily drinking could not be investigated, as the number of women $(n=61)$ who reported alcohol consumption greater than one glass a day was too small for meaningful analysis to be carried out. Participants and their partners were also asked how many days in the previous month they had drunk the equivalent of two pints of beer, four glasses of wine or four pub measures of spirit or more. Prompts were, Never, 1-2, 3-4, 5-10, 10+ d, everyday, which were recoded into: Never, $1-4,5-10,10+\mathrm{d}$. This question aimed to identify a tendency of consuming greater amounts of alcohol on each single drinking session (often referred to as "binging" or "binge drinking"). The question was also asked of a subsample of mothers at 32 wk gestation. There were 3224 cases in the whole cohort with complete data on maternal drinking at 18 and $32 \mathrm{wk}$ and paternal drinking during pregnancy.

Tobacco consumption was assessed by asking mothers and their partners how often they smoked $30+, 25-29,20-24,15-19,10-14,5-9,1-4,0$ cigarettes (during the first 3 mo of pregnancy). Participants were grouped in the following categories: No smoker, smoked 1-9/d, 10-19/d, 20+/d.

Assessment of potential confounders. Measures of socio-economic position were obtained by maternal self-reported questionnaires at approximately 8 wk gestation. They included maternal marital status (never married, widowed/divorced/separated, married/cohabiting); head of household occupational social class (classified according to the British Registrar generals classification: professional, managerial, skilled nonmanual, skilled manual, semiskilled manual, unskilled manual); home ownership (mortgaged/owned/ rented); and an index indicating the crowding condition of the household 
Table 1. Comparisons between participants remaining in the study and those with missing data at 8-y follow-up

\begin{tabular}{|c|c|c|c|c|}
\hline & $N$ & Still in the study $(n=4332)$ & Missing $(n=8980)$ & \\
\hline \multicolumn{5}{|l|}{ Sex } \\
\hline Males & 6861 & 50.1 & 52.5 & \\
\hline Females & 6418 & 50.0 & 47.6 & $x^{2}=6.77, p<0.05$ \\
\hline \multicolumn{5}{|l|}{ Parity } \\
\hline No previous children & 5804 & 48.2 & 42.4 & \\
\hline $1-2$ children & 6456 & 48.0 & 50.0 & \\
\hline $3+$ children & 830 & 3.8 & 7.6 & $x^{2}=90.99, p<0.001$ \\
\hline \multicolumn{5}{|l|}{ Ethnicity } \\
\hline White & 12,298 & 97.5 & 90.8 & \\
\hline Nonwhite & 660 & 2.4 & 6.3 & $x^{2}=220.91, p<0.001$ \\
\hline \multicolumn{5}{|l|}{ Home ownership status } \\
\hline Mortgaged/owned & 9457 & 86.9 & 67.4 & \\
\hline Rented & 3318 & 13.1 & 32.6 & $x^{2}=563.87, p<0.001$ \\
\hline \multicolumn{5}{|l|}{ House crowding } \\
\hline 1 & 5281 & 52.6 & 36.4 & \\
\hline 2 & 6467 & 44.5 & 55.0 & \\
\hline 3 or 4 & 838 & 2.9 & 8.6 & $x^{2}=378.03, p<0.001$ \\
\hline \multicolumn{5}{|l|}{ Maternal education } \\
\hline Degree & 1592 & 18.7 & 10.0 & \\
\hline A levels & 2757 & 28.0 & 19.7 & \\
\hline O levels & 4239 & 35.3 & 34.5 & \\
\hline Vocational/CSE & 3593 & 18.0 & 35.8 & $x^{2}=547.40, p<0.001$ \\
\hline \multicolumn{5}{|c|}{ Maternal alcohol use: 1 st 3 months in pregnancy } \\
\hline Never & 5982 & 44.6 & 46.0 & \\
\hline$<1$ glass a week & 5090 & 41.5 & 37.4 & \\
\hline $1-6$ a week & 1826 & 12.6 & 14.5 & \\
\hline 1 glass + per day & 251 & 1.4 & 2.2 & $x^{2}=30.29, p<0.001$ \\
\hline \multicolumn{5}{|c|}{ Maternal drinking frequency of $4+$ units } \\
\hline Never & 10,882 & 86.7 & 81.3 & \\
\hline $1-4 \mathrm{~d}$ & 1664 & 10.3 & 13.9 & \\
\hline $5-10 \mathrm{~d}$ & 267 & 1.4 & 2.3 & \\
\hline $10+d$ & 289 & 1.5 & 2.5 & $x^{2}=63.05, p<0.001$ \\
\hline \multicolumn{5}{|c|}{ Maternal tobacco use in pregnancy } \\
\hline No smoker & 9967 & 84.7 & 70.6 & \\
\hline 1-9 cigarettes a day & 1452 & 8.5 & 12.1 & \\
\hline $10-19$ cigarettes a day & 1325 & 5.4 & 12.2 & \\
\hline $20+$ cigarettes a day & 512 & 1.3 & 5.1 & $x^{2}=355.49, p<0.001$ \\
\hline \multicolumn{5}{|l|}{ Paternal education } \\
\hline Degree & 2158 & 25.3 & 14.4 & \\
\hline A levels & 3080 & 29.3 & 24.5 & \\
\hline O levels & 2499 & 22.4 & 20.7 & \\
\hline Vocational/CSE & 3988 & 23.0 & 40.5 & $x^{2}=449.47, p<0.001$ \\
\hline \multicolumn{5}{|c|}{ Paternal self-reports of alcohol and tobacco use in pregnancy } \\
\hline \multicolumn{5}{|c|}{ Paternal alcohol use: previous 3 mo during mother's pregnancy } \\
\hline Never & $482^{\circ}$ & 3.2 & 6.3 & \\
\hline$<1$ glass a week & 2393 & 22.5 & 26.0 & \\
\hline $1-6$ a week & 4912 & 52.5 & 48.5 & \\
\hline 1 glass + per day & 1992 & 21.8 & 19.2 & $x^{2}=74.24, p<0.001$ \\
\hline \multicolumn{5}{|c|}{ Paternal drinking frequency of $4+$ units } \\
\hline Never & 1836 & 16.07 & 20.55 & \\
\hline $1-4 \mathrm{~d}$ & 3642 & 38.07 & 35.93 & \\
\hline $5-10 \mathrm{~d}$ & 2497 & 26.78 & 24.10 & \\
\hline $10+d$ & 1904 & 19.09 & 19.42 & $x^{2}=36.35, p<0.001$ \\
\hline \multicolumn{5}{|c|}{ Paternal tobacco use in pregnancy } \\
\hline No smoker & 5924 & 70.0 & 56.3 & \\
\hline $1-9$ cigarettes a day & 896 & 9.5 & 9.4 & \\
\hline $10-19$ cigarettes a day & 1367 & 10.7 & 17.6 & \\
\hline $20+$ cigarettes a day & 1285 & 9.8 & 16.8 & $x^{2}=231.03, p<0.001$ \\
\hline
\end{tabular}

(calculated by dividing the number of people in the household by the number of rooms); and maternal reports of the child's ethnicity (whites, non-whites). Gender of the child was extracted from the obstetric data. Maternal parity (no previous children, $1-2$ children, $3+$ children) was obtained at 18 wk gestation, as was education. Mothers were asked to report the highest levels of educational qualifications achieved by her and her partner (Degree, A levels, O levels, Vocational/CSE).
Statistical analyses. Univariable associations between maternal and paternal patterns of alcohol and tobacco use during pregnancy and child's IQ were assessed by presenting the means and standard deviations of child's IQ scores by categories of maternal and paternal patterns of alcohol and tobacco consumption. We then tabulated the maternal and paternal drinking and maternal and paternal smoking by the main confounders (Tables S1-S6, supplementary material online at www.pedresearch.org). 
We used linear regression to estimate mean differences and $95 \% \mathrm{CI}$ in IQ scores across the exposure categories. Then we fitted a series of multivariable linear regression models to assess the independent effect per category, respectively, of alcohol and tobacco on IQ. We progressively adjusted for sex, social class, parity, ethnicity, house ownership and crowding (Model 2), maternal and paternal education (Model 3), paternal and maternal smoking in the regression for the association with alcohol, and paternal and maternal drinking in the regression for the association with smoking (Model 4). Model 5 included adjustment for paternal effects in the maternal model and adjustment for maternal effects in the paternal model. We computed an $f$ statistic to formally compare the unadjusted and adjusted coefficients of maternal and paternal associations for each model. The same analytical approach was used in logistic regression analysis to examine associations of maternal and paternal alcohol and tobacco exposure categories with low IQ (defined as a score of 79 or below).

Dealing with missing data. Analyses presented in this paper were conducted on 4332 study participants (approximately 32\% of the eligible live born singletons children who were still alive at $1 \mathrm{y}$ ) with complete data on maternal and paternal smoking and alcohol consumption at the time that the mother was pregnant with the offspring participant, offspring IQ at age 8 and all confounding variables. We explored the extent to which missing data might have biased our results in a number of ways. First, we used multivariate multiple imputation, using chained equations. We used the STATA procedure developed by Royston (27), with 20 cycles of regression switching and generated 20 imputation data sets. Variables used in the imputation models included all available measures of maternal and paternal alcohol and tobacco use, all indicators of socioeconomic position, housing, mothers and partners' education, and maternal parity (full prediction model available from the corresponding author on request). We repeated the multivariable regression analyses on the imputed data sets. Second, because the inclusion of paternal reports was an important source of missing data, we repeated all multivariable analysis using maternal and child's data only. In this analysis, it was not possible to undertake parental comparisons of effect (which was our main aim) but we could examine whether the exclusion of those without information on their fathers resulted in biased estimates of the maternal associations. All analyses were conducted using STATA $9.2(28)$.

\section{RESULTS}

Table 1 shows the characteristics of participants included in the main analyses (complete case analysis) compared with those with missing data on any of the variables included in the multivariable models. Although some missing data arises from fewer paternal reports, most missing data arises from loss to follow-up, with $32.5 \%$ of the original cohort having IQ results at age 8. Participants lost to follow-up were more likely to be men, their mothers and partners were more likely to report lower levels of educational attainment and to have lived in rented and crowded accommodation at the time of their pregnancy. In addition, there were differences in maternal and paternal tobacco and alcohol use between subjects with full and missing data.

Tables 2 and 3 show univariable associations (means and SD) between maternal and paternal patterns of alcohol and tobacco use during pregnancy and child's IQ scores at age 8 . Maternal patterns of alcohol consumption in the first $3 \mathrm{mo}$ of pregnancy were not associated with child's verbal, performance or total IQ score. By comparison, there was a positive association between paternal drinking and child's IQ scores (greater consumption of alcohol by fathers being associated with higher IQ scores). There was a weak inverse association between frequency of maternal drinking of four or more units and child's IQ scores, with no association between fathers' "binge drinking" (frequency of drinking more than 4 units) and child's total IQ scores.

Table 2. Univariable associations between maternal and paternal patterns of alcohol consumption during pregnancy and child's IQ scores $[$ means $(S D)]$ at age 8 (complete case analysis, $n=4332$ )

\begin{tabular}{|c|c|c|c|c|c|c|c|c|c|c|}
\hline \multicolumn{11}{|c|}{ Maternal and paternal patterns of alcohol use in pregnancy } \\
\hline & \multicolumn{2}{|c|}{$\begin{array}{c}\text { Never } \\
1930\end{array}$} & \multicolumn{2}{|c|}{$\begin{array}{c}<1 \mathrm{wk} \\
1796\end{array}$} & \multicolumn{2}{|c|}{$\begin{array}{c}1+w k \\
545\end{array}$} & \multicolumn{2}{|c|}{$\begin{array}{c}1+/ \mathrm{d} \\
61\end{array}$} & \multirow[t]{2}{*}{$p^{*}$} & \multirow[t]{2}{*}{$p_{\dagger}^{\dagger}$} \\
\hline \multicolumn{9}{|c|}{ Mothers: 1 st 3 mo of pregnancy } & & \\
\hline WISC-Verbal & 108.6 & $(16.5)$ & 109.2 & $(16.7)$ & 110.3 & $(15.6)$ & 108.8 & $(17.2)$ & 0.16 & 0.04 \\
\hline WISC-Performance & 101.1 & $(16.8)$ & 101.5 & $(16.8)$ & 102.0 & $(17.0)$ & 98.6 & $(16.3)$ & 0.49 & 0.49 \\
\hline WISC-Total & 105.7 & $(16.2)$ & 106.4 & $(16.3)$ & 107.3 & $(15.6)$ & 104.6 & $(15.2)$ & 0.10 & 0.10 \\
\hline & \multicolumn{2}{|c|}{ Never } & \multicolumn{2}{|c|}{$<1$ wk } & \multicolumn{2}{|c|}{$1+w k$} & \multicolumn{2}{|c|}{$1+w k$} & $p^{*}$ & $p^{\dagger}$ \\
\hline \multicolumn{11}{|c|}{ Fathers: previous 3 mo during mother's pregnancy } \\
\hline WISC-Verbal & 104.6 & $(16.1)$ & 106.7 & $(17.3)$ & 109.3 & $(16.0)$ & 111.7 & $(16.5)$ & $<0.001$ & $<0.001$ \\
\hline WISC-Performance & 99.3 & $(18.2)$ & 99.9 & $(16.8)$ & 101.7 & (16.6) & 102.3 & $(17.0)$ & $<0.001$ & $<0.001$ \\
\hline WISC-Total & 102.2 & $(16.8)$ & 104.0 & $(16.7)$ & 106.5 & $(15.8)$ & 108.3 & $(16.1)$ & $<0.001$ & $<0.001$ \\
\hline \multicolumn{11}{|c|}{ Maternal and paternal 'binging' patterns of alcohol use in pregnancy } \\
\hline & \multicolumn{2}{|c|}{$\begin{array}{c}\text { Never } \\
3755\end{array}$} & \multicolumn{2}{|c|}{$\begin{array}{c}1-4 \mathrm{~d} \\
448\end{array}$} & \multicolumn{2}{|c|}{$\begin{array}{c}5-10 d \\
63 \\
\end{array}$} & \multicolumn{2}{|c|}{$\begin{array}{c}10+\mathrm{d} \\
66 \\
\end{array}$} & $p^{*}$ & $p^{\dagger}$ \\
\hline \multicolumn{11}{|c|}{ Mothers: drinking frequency of four or more units } \\
\hline WISC-Verbal & 109.5 & $(16.6)$ & 106.0 & $(15.8)$ & 108.3 & $(13.5)$ & 104.7 & $(15.0)$ & $<0.001$ & $<0.001$ \\
\hline WISC-Performance & 101.5 & $(16.9)$ & 100.3 & $(16.3)$ & 99.9 & $(17.7)$ & 100.2 & $(13.1)$ & $<0.42$ & $<0.15$ \\
\hline \multirow[t]{2}{*}{ WISC-Total } & 106.5 & $(16.3)$ & 103.7 & $(15.6)$ & 105.0 & $(15.5)$ & 103.1 & $(13.8)$ & $<0.001$ & $<0.001$ \\
\hline & \multicolumn{2}{|c|}{$\begin{array}{c}\text { Never } \\
696\end{array}$} & \multicolumn{2}{|c|}{$\begin{array}{c}1-4 \mathrm{~d} \\
1649\end{array}$} & \multicolumn{2}{|c|}{$\begin{array}{c}5-10 \mathrm{~d} \\
1160\end{array}$} & \multicolumn{2}{|c|}{$\begin{array}{c}10+\mathrm{d} \\
827\end{array}$} & $p^{*}$ & $p^{\dagger}$ \\
\hline \multicolumn{11}{|c|}{ Fathers: drinking frequency of four or more units } \\
\hline WISC-Verbal & 107.8 & $(17.6)$ & 109.2 & $(16.6)$ & 109.8 & $(15.9)$ & 108.9 & $(16.4)$ & 0.09 & 0.18 \\
\hline WISC-Performance & 100.9 & $(17.0)$ & 101.5 & $(16.9)$ & 102.1 & $(16.7)$ & 100.4 & $(16.8)$ & 0.13 & 0.69 \\
\hline WISC-Total & 105.1 & $(17.0)$ & 106.3 & $(16.2)$ & 107.0 & $(15.6)$ & 105.5 & $(16.0)$ & 0.05 & 0.51 \\
\hline
\end{tabular}

$* p$ for linear association.

$\dagger p$ for nonlinear association. 
Table 3. Univariable associations between maternal and paternal patterns of tobacco use during pregnancy and child's IQ scores $[$ means $(S D)]$ at age 8 (complete case analysis, $n=4332$ )

\begin{tabular}{|c|c|c|c|c|c|c|c|c|c|c|}
\hline \multicolumn{11}{|c|}{ Maternal and paternal patterns of tobacco use during pregnancy } \\
\hline & \multicolumn{2}{|c|}{$\begin{array}{c}\text { No smoker } \\
3671\end{array}$} & \multicolumn{2}{|c|}{$\begin{array}{c}1-9 / \mathrm{d} \\
369\end{array}$} & \multicolumn{2}{|c|}{$\begin{array}{c}10-19 / \mathrm{d} \\
235\end{array}$} & \multicolumn{2}{|c|}{$\begin{array}{c}20+/ \mathrm{d} \\
57\end{array}$} & \multirow[t]{2}{*}{$p^{*}$} & \multirow[t]{2}{*}{$p^{\dagger}$} \\
\hline Mothers: patterns of to & use & & & & & & & & & \\
\hline WISC-Verbal & 109.6 & $(16.5)$ & 106.4 & $(15.9)$ & 105.3 & $(16.4)$ & 104.3 & $(17.9)$ & $<0.001$ & $<0.001$ \\
\hline WISC-Performance & 101.9 & $(16.9)$ & 100.3 & $(16.1)$ & 96.1 & $(15.7)$ & 94.6 & $(15.4)$ & $<0.001$ & $<0.001$ \\
\hline \multirow[t]{2}{*}{ WISC-Total } & 106.8 & $(16.2)$ & 104.1 & $(15.4)$ & 101.3 & $(15.5)$ & 99.7 & $(15.8)$ & $<0.001$ & $<0.001$ \\
\hline & \multicolumn{2}{|c|}{$\begin{array}{c}\text { No smoker } \\
3031\end{array}$} & \multicolumn{2}{|c|}{$\begin{array}{c}1-9 / \mathrm{d} \\
413\end{array}$} & \multicolumn{2}{|c|}{$\begin{array}{c}10-19 / \mathrm{d} \\
464\end{array}$} & \multicolumn{2}{|c|}{$\begin{array}{c}20+/ d \\
424\end{array}$} & $p^{*}$ & $p^{\dagger}$ \\
\hline \multicolumn{11}{|c|}{ Fathers: patterns of tobacco use } \\
\hline WISC-Verbal & 110.1 & $(16.5)$ & 108.9 & $(16.5)$ & 105.7 & $(16.1)$ & 105.3 & $(16.4)$ & $<0.001$ & $<0.001$ \\
\hline WISC-Performance & 102.0 & $(16.9)$ & 101.0 & $(16.3)$ & 99.1 & $(17.2)$ & 99.2 & $(16.2)$ & $<0.001$ & $<0.001$ \\
\hline WISC-Total & 107.2 & $(16.2)$ & 106.0 & (15.9) & 103.0 & $(16.2)$ & 102.7 & $(15.4)$ & $<0.001$ & $<0.001$ \\
\hline
\end{tabular}

* $p$ for linear association.

$\dagger p$ for nonlinear association.

Both maternal and paternal tobacco use were inversely associated with all WISC IQ scales. All maternal and paternal smoking and alcohol measures were associated with potential confounding factors, with the one exception that maternal "binge drinking" was not associated with ethnicity (Tables S1-S6, supplementary material online at www.pedresearch.org).
Table 4 shows complete case analysis and analyses conducted on the imputed datasets for the mean change of offspring IQ per increase in maternal and paternal categories of alcohol and tobacco use, and the $p$-value for the difference between maternal and paternal associations. The positive association of amount of alcohol consumed by partners in the first 3 mo of pregnancy and offspring IQ attenuated toward the

Table 4. Mean change in offspring IQ per increase in maternal and paternal alcohol and tobacco categories

\begin{tabular}{|c|c|c|c|c|c|c|}
\hline & $\begin{array}{l}\text { Mean change in } \\
\text { offspring IQ per } \\
\text { increase in maternal } \\
\text { alcohol category }\end{array}$ & $\begin{array}{l}\text { Mean change in } \\
\text { offspring IQ per } \\
\text { increase in paternal } \\
\text { alcohol category }\end{array}$ & $\begin{array}{c}p \text {-value for difference } \\
\text { between maternal } \\
\text { and paternal } \\
\text { associations }\end{array}$ & $\begin{array}{l}\text { Mean change in } \\
\text { offspring IQ per } \\
\text { increase in maternal } \\
\text { alcohol category }\end{array}$ & $\begin{array}{l}\text { Mean change in } \\
\text { offspring IQ per } \\
\text { increase in paternal } \\
\text { alcohol category }\end{array}$ & $\begin{array}{l}p \text {-value for difference } \\
\text { between maternal } \\
\text { and paternal } \\
\text { associations }\end{array}$ \\
\hline & \multicolumn{3}{|c|}{ Complete case analyses $(n=4332)$} & \multicolumn{3}{|c|}{ Analyses using 20 imputated datasets $(n=13,617)$} \\
\hline & \multicolumn{3}{|c|}{ Amount of alcohol in first 3 mo of pregnancy } & \multicolumn{3}{|c|}{ Amount of alcohol in first 3 mo of pregnancy } \\
\hline Model 1 & $0.55(-0.11,1.20)$ & $1.38(0.94,1.81)$ & 0.005 & $0.76(0.11,1.41)$ & $1.01(-1.00,3.01)$ & 0.72 \\
\hline Model 2 & $0.68(0.03,1.33)$ & $1.17(0.74,1.60)$ & 0.08 & $0.67(0.05,1.29)$ & $0.77(-0.62,2.16)$ & 0.81 \\
\hline Model 3 & $0.14(-0.46,0.74)$ & $0.41(0.00,0.81)$ & 0.43 & $0.41(-0.26,1.07)$ & $0.40(-0.68,1.47)$ & 0.95 \\
\hline Model 4 & $0.15(-0.46,0.75)$ & $0.41(0.00,0.82)$ & 0.43 & $0.30(-0.34,0.94)$ & $0.45(-0.02,0.91)$ & 0.55 \\
\hline Model 5 & $0.03(-0.58,0.65)$ & $0.40(-0.01,0.82)$ & 0.43 & $0.18(-0.47,0.82)$ & $0.43(-0.04,0.89)$ & 0.55 \\
\hline & \multicolumn{3}{|c|}{ Drinking frequency of $4+$ units } & \multicolumn{3}{|c|}{ Drinking frequency of $4+$ units } \\
\hline Model 1 & $-1.60(-2.53,-0.67)$ & $0.16(-0.33,0.66)$ & 0.001 & $-1.63(-2.40,-0.87)$ & $1.48(0.78,2.18)$ & 0.001 \\
\hline Model 2 & $-1.10(-2.02,-0.18)$ & $0.04(-0.45,0.53$ & 0.03 & $-1.09(-1.85,-0.33)$ & $0.91(0.33,1.49)$ & \\
\hline Model 3 & $-0.41(-1.26,0.45)$ & $0.07(-0.39,0.52)$ & 0.38 & $-0.62(-1.34,0.11)$ & $0.68(0.08,1.28)$ & 0.002 \\
\hline Model 4 & $-0.42(-1.28,0.44)$ & $0.06(-0.40,0.52)$ & 0.38 & $-0.62(-1.44,0.21)$ & $0.16(-0.39,0.72)$ & 0.11 \\
\hline \multirow[t]{4}{*}{ Model 5} & $-0.45(-1.32,0.43)$ & $0.10(-0.36,0.56)$ & 0.38 & $-0.62(-1.44,0.21)$ & $0.16(-0.39,0.72)$ & 0.11 \\
\hline & $\begin{array}{l}\text { Mean change in } \\
\text { offspring IQ per } \\
\text { increase in maternal } \\
\text { tobacco category }\end{array}$ & $\begin{array}{l}\text { Mean change in } \\
\text { offspring IQ per } \\
\text { increase in paternal } \\
\text { tobacco category }\end{array}$ & $\begin{array}{c}p \text {-value for difference } \\
\text { between maternal } \\
\text { and paternal } \\
\text { associations }\end{array}$ & $\begin{array}{l}\text { Mean change in } \\
\text { offspring IQ per } \\
\text { increase in maternal } \\
\text { tobacco category }\end{array}$ & $\begin{array}{l}\text { Mean change in } \\
\text { offspring IQ per } \\
\text { increase in paternal } \\
\text { tobacco category }\end{array}$ & $\begin{array}{c}p \text {-value for difference } \\
\text { between maternal } \\
\text { and paternal } \\
\text { associations }\end{array}$ \\
\hline & \multicolumn{3}{|c|}{ Complete case analyses $(n=4332)$} & \multicolumn{3}{|c|}{ Analyses using 20 imputated datasets $(n=13,617)$} \\
\hline & \multicolumn{3}{|c|}{ Tobacco use in pregnancy } & \multicolumn{3}{|c|}{ Tobacco use in pregnancy } \\
\hline Model 1 & $-2.63(-3.42,-1.84)$ & $-1.65(-2.12,-1.18)$ & 0.27 & $-2.32(-2.93,-1.71)$ & $-0.96(-1.57,-0.34)$ & 0.001 \\
\hline Model 2 & $-1.78(-2.59,-0.97)$ & $-1.04(-1.53,-0.56)$ & 0.29 & $-1.09(-1.72,-0.47)$ & $-0.43(-1.04,0.18)$ & 0.02 \\
\hline Model 3 & $0.05(-0.71,0.81)$ & $0.50(-1.06,1.71)$ & 0.79 & $-0.10(-0.75,0.54)$ & $0.19(-0.38,0.76)$ & 0.27 \\
\hline Model 4 & $0.08(-0.69,0.85)$ & $0.12(-0.34,0.58)$ & 0.87 & $-0.08(-0.69,0.94)$ & $0.22(-0.77,1.21)$ & 0.93 \\
\hline Model 5 & $0.08(-0.69,0.85)$ & $0.12(-0.36,0.59)$ & 0.87 & $-0.07(-0.65,0.50)$ & $-0.11(-0.79,0.57)$ & 0.92 \\
\hline
\end{tabular}

Model 1: unadjusted.

Model 2: adjusted by sex, social class, parity, ethnicity, house ownership, and crowding.

Model 3: Model 2+ maternal and paternal education.

Model 4: Model 3+ paternal and maternal smoking in the regression for the association with alcohol, and paternal and maternal drinking in the regression for the association with smoking.

Model 5: Model 4+ paternal effects in the maternal model and maternal effects in the paternal model. 
null when adjustment for parental education was entered in the model. The inverse association of maternal "binge" drinking also attenuated to the null with adjustment for parental education, as did the inverse associations of maternal and paternal smoking with offspring IQ. In the fully adjusted models, there was no statistical evidence of a difference in association between maternal alcohol/tobacco-offspring IQ compared with paternal alcohol/tobacco-offspring IQ for any measures of exposure. Analysis conducted on the imputed data sets did not show any substantive difference from the complete case analyses. There was also no statistical evidence of increased risk in those achieving IQ scores $<79$, and no evidence of a difference in association between maternal alcohol/tobaccooffspring IQ compared with paternal alcohol/tobaccooffspring IQ for any of the exposure measures (Table 5).

In analyses that were restricted to 5688 mothers and children pairs (i.e. not excluding those without partner data), the results were essentially the same as those presented in the subsample who did have data on partners for the associations of maternal daily alcohol and tobacco use with IQ. The point estimates for "binge" drinking were slightly elevated in these 5688 participants compared with the restricted analyses. For example, in the fully adjusted model, the mean change in offspring IQ per increase in maternal "binge" drinking alcohol categories was $-0.66(-1.39,0.06)$ in the larger sample compared with $-0.45(-1.32,0.43)$ (Table 4) among those with partner data. Finally, in analyses which were restricted to the 3224 cases with complete data on maternal drinking at 18 and $32 \mathrm{wk}$ and paternal drinking during pregnancy, we found results similar to those reported in the main analysis. In the fully adjusted model, the mean change in offspring IQ per increase in maternal "binge" drinking alcohol categories was
$-0.33(-1.36,0.70)$ whereas increase in paternal "binge" drinking alcohol categories was $0.08(-0.60,0.44)$ with no evidence of a significant difference between maternal and paternal associations ( $p$-value $=0.70$ ) (data not shown).

Overall, both alcohol and tobacco use during pregnancy (whether maternal or paternal) explained very little $(0.04 \%)$ of the variation in child's IQ at age 8. By far the strongest associations with IQ were maternal and paternal education, which together explained nearly $19 \%$ of the variation in IQ at child age 8 .

\section{DISCUSSION}

In this paper, we examined whether there was a relationship between maternal alcohol and tobacco consumption in pregnancy and IQ in childhood, and tested epidemiologically whether there was a similar association between paternal consumption of alcohol and tobacco and childhood IQ, to that of the equivalent maternal association. To our knowledge, this is the first study to explore the specific intrauterine effects of both these exposures by comparing maternal to paternal effects. In univariable analyses, greater frequency of drinking four or more units on a single occasion by mothers was associated with lower scores on verbal and total IQ scales in children. Greater quantity of alcohol consumed by fathers was, in contrast, associated with higher scores on all IQ scales in univariable analyses. In adjusted analyses, however, we found no strong evidence of an intrauterine effect of alcohol consumption in first 3 mo of pregnancy by mothers or fathers and variation in childhood mean IQ (Table 4) or prevalence of low IQ (Table 5). The univariable associations appeared to be a product of socio-economic confounding in that mothers

Table 5. Multivariable associations between maternal alcohol/tobacco use and offspring IQ below 79 [OR (95\% CI)] (Complete case analyses $n=4332$ )

\begin{tabular}{|c|c|c|c|}
\hline & $\begin{array}{c}\text { Maternal alcohol/tobacco use and offspring } \\
\text { low IQ }(<79)[\text { OR }(95 \% \text { CI })]\end{array}$ & $\begin{array}{c}\text { Paternal alcohol/tobacco use and offspring } \\
\text { low IQ [OR (95\% CI)] }\end{array}$ & $\begin{array}{c}p \text {-value for difference between maternal and } \\
\text { paternal associations }\end{array}$ \\
\hline \multicolumn{4}{|c|}{ Amount of alcohol in first 3 mo of pregnancy } \\
\hline Model 1 & $0.85(0.70,1.03)$ & $0.77(0.67,0.88)$ & 0.48 \\
\hline Model 2 & $0.83(0.68,1.01)$ & $0.79(0.69,0.90)$ & 0.48 \\
\hline Model 3 & $0.87(0.71,1.06)$ & $0.86(0.75,0.99)$ & 0.81 \\
\hline Model 4 & $0.87(0.71,1.06)$ & $0.86(0.75,0.99)$ & 0.80 \\
\hline Model 5 & $0.90(0.74,1.11)$ & $0.87(0.76,1.01)$ & 0.80 \\
\hline \multicolumn{4}{|c|}{ Drinking frequency of $4+$ units } \\
\hline Model 1 & $1.13(0.89,1.43)$ & $0.96(0.84,1.11)$ & 0.22 \\
\hline Model 2 & $1.08(0.84,1.38)$ & $0.98(0.85,1.12)$ & 0.46 \\
\hline Model 3 & $0.99(0.77,1.27)$ & $0.98(0.85,1.13)$ & 0.91 \\
\hline Model 4 & $0.99(0.77,1.28)$ & $0.98(0.85,1.13)$ & 0.90 \\
\hline Model 5 & $1.00(0.77,1.29)$ & $0.98(0.85,1.13)$ & 0.91 \\
\hline \multicolumn{4}{|c|}{ Tobacco use in pregnancy } \\
\hline Model 1 & $1.22(0.99,1.46)$ & $1.17(1.04,1.32)$ & 0.83 \\
\hline Model 2 & $1.10(0.90,1.36)$ & $1.10(0.97,1.25)$ & 0.85 \\
\hline Model 3 & $0.92(0.74,1.13)$ & $0.97(0.85,1.11)$ & 0.65 \\
\hline Model 4 & $0.93(0.75,1.14)$ & $0.97(0.85,1.11)$ & 0.70 \\
\hline Model 5 & $0.93(0.75,1.16)$ & $0.99(0.86,1.13)$ & 0.70 \\
\hline
\end{tabular}

Model 1: Unadjusted.

Model 2: Adjusted by sex, social class, parity, ethnicity, house ownership, and crowding.

Model 3: Model 2+ maternal and paternal education.

Model 4: Model 3+ paternal and maternal smoking in the regression for the association with alcohol, and paternal and maternal drinking in the regression for the association with smoking.

Model 5: Model 4+ paternal effects in the maternal model and maternal effects in the paternal model. 
reporting higher frequency of "binge" drinking in pregnancy tended to have lower educational attainment whereas fathers reporting higher alcohol consumption had higher educational attainment (Tables S1-S6, supplementary material online at www.pedreserach.org). Parental educational attainment was strongly associated with offspring IQ.

We also explored associations for mothers' exposures only and did not restrict the analysis sample to those with partner data. In this analysis, there was some evidence that the exclusion of those who did not have paternal data might have resulted in an underestimation of the association of maternal "binge" drinking with child's IQ, though there was no strong statistical evidence of an association even in this group. Nonetheless, few women in this study reported "binge" drinking in early pregnancy. Therefore, our results should not be interpreted as showing that "binge" drinking does not affect child's IQ, but larger studies with greater variation in alcohol consumption in mothers and fathers recorded across the whole period of pregnancy are required to explore this further.

Both maternal and paternal tobacco consumption during pregnancy were associated with lower offspring IQ in univariable analyses (Table 3), but again this effect or any difference in effect between maternal and paternal tobacco consumption, was no longer seen after adjustment for parental education (Tables 4 and 5). Thus, our findings provide no strong evidence for the assertion that intrauterine exposure to tobacco affects offspring cognitive development and later IQ.

We used data from the ALSPAC longitudinal study, one of the few, large studies in the world with the capacity to adopt a robust methodological approach to test the effect of residual confounding due to paternal, environmental, and social influences.

Our findings should be considered in the context of some limitations, the most notable of which was the extent of missing data both due to loss to follow-up in the cohort and missing paternal data. To address this limitation, we have presented analysis on a dataset with 20 imputed datasets. These results suggest that our overall conclusions are not importantly influenced by selection bias due to missing data. Like most previous studies, we used self-reports of alcohol and tobacco use in pregnancy, which were not validated by objective measurements of cotinine levels (in the case of tobacco use) or biomarkers such as gamma-glutamyltransferase (in the case of alcohol use). Any measurement error in these exposures is likely to be nondifferential with respect to our outcome measure of childhood IQ, which would have the expectation of underestimating any associations. Our study has several conclusions. First, we have confirmed findings from previous studies that parental education is a major determinant of child IQ. Second, our findings suggest that once parental education is taken into account there is no strong evidence of an intrauterine effect of moderate alcohol consumption and smoking in early pregnancy on childhood IQ. These two findings together highlight the importance of properly adjusting for parental education in these associations. This requires adjusting for education in both parents and using a detailed graded measure of education because parental education is associated in a graded way with child's IQ. Finally, our study shows that very few women drink excessively throughout pregnancy, which means that very large studies are required to determine the precise detrimental effects of excessive maternal and prolonged alcohol consumption in pregnancy. Although our findings do not suggest that maternal smoking during pregnancy has a direct effect on offspring IQ, it is clear that young women should be supported not to smoke both for their own health and that of their offspring. Therefore, our results in no way contradict the sound advice to pregnant women that they limit alcohol consumption (some authorities recommend to abstain from alcohol altogether) (29) while pregnant.

Acknowledgments. We are grateful to the families who took part in this study, the midwives for their help in recruiting them, and the whole ALSPAC team, which includes interviewers, computer and laboratory technicians, clerical workers, research scientists, volunteers, managers, receptionists and nurses.

\section{REFERENCES}

1. Breslau N, Paneth N, Lucia VC, Paneth-Pollak R 2005 Maternal smoking during pregnancy and offspring IQ. [see comment]. Int J Epidemiol 34:1047-1053

2. Lawlor DA, Batty GD, Morton SM, Deary IJ, Macintyre S, Ronalds G, Leon DA 2005 Early life predictors of childhood intelligence: evidence from the Aberdeen children of the 1950s study. J Epidemiol Community Health 59:656-663

3. Lawlor DA, Clark H, Smith GD, Leon DA 2006 Intrauterine growth and intelligence within sibling pairs: findings from the Aberdeen children of the 1950s cohort. Pediatrics 117:e894-e902

4. Lawlor DA, Najman JM, Batty GD, O'Callaghan MJ, Williams GM, Bor W 2006 Early life predictors of childhood intelligence: findings from the Mater-University study of pregnancy and its outcomes. Paediatr Perinat Epidemiol 20:148-162

5. O'Leary CM 2004 Fetal alcohol syndrome: diagnosis, epidemiology, and developmental outcomes. J Paediatr Child Health 40:2-7

6. Testa M, Quigley BM, Eiden RD 2003 The effects of prenatal alcohol exposure on infant mental development: a meta-analytical review. Alcohol Alcohol 38:295-304

7. Olson HC, Streissguth AP, Sampson PD, Barr HM, Bookstein FL, Thiede K 1997 Association of prenatal alcohol exposure with behavioral and learning problems in early adolescence. J Am Acad Child Adolesc Psychiatry 36:1187-1194

8. Streissguth AP, Barr HM, Olson HC, Sampson PD, Bookstein FL, Burgess DM 1994 Drinking during pregnancy decreases word attack and arithmetic scores on standardized tests: adolescent data from a population-based prospective study. Alcohol Clin Exp Res 18:248-254

9. Streissguth AP, Barr HM, Sampson PD 1990 Moderate prenatal alcohol exposure: effects on child IQ and learning problems at age 7 1/2 years. Alcohol Clin Exp Res 14:662-669

10. O'Callaghan FV, O'Callaghan M, Najman JM, Williams GM, Bor W 2007 Prenatal alcohol exposure and attention, learning and intellectual ability at 14 years: a prospective longitudinal study. Early Hum Dev 83:115-123

11. Willford J, Leech S, Day N 2006 Moderate prenatal alcohol exposure and cognitive status of children at age 10. Alcohol Clin Exp Res 30:1051-1059

12. Richardson GA, Ryan C, Willford J, Day NL, Goldschmidt L 2002 Prenatal alcohol and marijuana exposure: effects on neuropsychological outcomes at 10 years. Neurotoxicol Teratol 24:309-320

13. Willford JA, Richardson GA, Leech SL, Day NL 2004 Verbal and visuospatial learning and memory function in children with moderate prenatal alcohol exposure. Alcohol Clin Exp Res 28:497-507

14. Sexton M, Fox NL, Hebel JR 1990 Prenatal exposure to tobacco: II. Effects on cognitive functioning at age three. Int J Epidemiol 19:72-77

15. Fried PA, O'Connell CM, Watkinson B 1992 60- and 72-month follow-up of children prenatally exposed to marijuana, cigarettes, and alcohol: cognitive and language assessment. [see comment]. J Dev Behav Pediatr 13:383-391

16. Batstra L, Hadders-Algra M, Neeleman J 2003 Effect of antenatal exposure to maternal smoking on behavioural problems and academic achievement in childhood: prospective evidence from a Dutch birth cohort. Early Hum Dev 75:21-33

17. Cornelius MD, Ryan CM, Day NL, Goldschmidt L, Willford JA 2001 Prenatal tobacco effects on neuropsychological outcomes among preadolescents. J Dev Behav Pediatr 22:217-225

18. Batty GD, Der G, Deary IJ 2006 Effect of maternal smoking during pregnancy on offspring's cognitive ability: empirical evidence for complete confounding in the US national longitudinal survey of youth. Pediatrics 118:943-950

19. Eskenazi B, Trupin LS 1995 Passive and active maternal smoking during pregnancy, as measured by serum cotinine, and postnatal smoke exposure. II. Effects on neurodevelopment at age 5 years. Am J Epidemiol 142:S19-S29 
20. Fergusson DM, Lloyd M 1991 Smoking during pregnancy and its effects on child cognitive ability from the ages of 8 to 12 years. Paediatr Perinat Epidemiol 5:189-200

21. Fried PA, Watkinson B, Gray R 1998 Differential effects on cognitive functioning in 9- to 12-year olds prenatally exposed to cigarettes and marihuana. Neurotoxicol Teratol 20:293-306

22. Fried PA, Watkinson B, Siegel LS 1997 Reading and language in 9- to 12-year olds prenatally exposed to cigarettes and marijuana. Neurotoxicol Teratol 19:171-183

23. Smith GD 2008 Assessing intrauterine influences on offspring health outcomes: can epidemiological studies yield robust findings? Basic Clin Pharmacol Toxicol 102:245-256

24. Golding J, Pembrey M, Jones R; ALSPAC Study Team 2001 ALSPAC-the Avon Longitudinal Study of Parents and Children. I. Study methodology. Paediatr Perinat Epidemiol 15:74-87
25. Wechsler D 1992 Wechsler Intelligence Scale for Children-3rd UK ed (WISC - III UK). Sidcup, UK: The Psychological Corporation

26. Northstone K, Bonnell S, Horwood J, Bell C, Sadler S, Carmichael A Team TFaS 2005 Children of the $90 \mathrm{~s}$ - Focus at 8: Built Files Documentation. Avon Longitudinal Study of Parents and Children, Bristol, pp 1-155

27. Royston P 2005 Multiple imputation of missing values: update of ice. Stata Journal 5:527-536

28. StataCorp 2005 Stata Statistical Software: Release 9. StataCorp LP, College Station, TX

29. U.S. Department of Health and Human Services and U.S. Department of Agriculture January 2005 Dietary Guidelines for Americans. 6th ed. Washington, DC: U.S. Government Printing Office 